\title{
DINÂMICA DA BIOMASSA E CARBONO ARBÓREO ENTRE 1995-2012 EM FLORESTA OMBRÓFILA MISTA MONTANA
}

\author{
Evelyn Takahashi Lipinski ${ }^{1}$, Ana Paula Dalla Corte ${ }^{2 *}$, Carlos Roberto Sanquetta ${ }^{2}$, Aurélio Lourenço Rodrigues ${ }^{3}$, \\ Francelo Mognon ${ }^{4}$, Alexandre Behling ${ }^{2}$
${ }^{1}$ Universidade Federal do Paraná, Programa de Pós Graduação em Engenheira Florestal, Curitiba, Paraná, Brasil - evelyn.tkhshi@gmail.com
${ }^{2}$ Universidade Federal do Paraná, Departamento de Ciências Florestais, Curitiba, Paraná, Brasil - anapaulacorte@ gmail.com*; carlos_sanquetta@hotmail.com; alexandre.behling@yahoo.com.br
${ }^{3}$ Companhia de Saneamento do Paraná (SANEPAR), Curitiba, Paraná, Brasil - aureliolr@ sanepar.com.br \\ ${ }^{4}$ Instituto Ambiental do Paraná, Departamento de Biodiversidade e Áreas Protegidas, Curitiba, Paraná, Brasil - francelo.iap@ gmail.com
}

Recebido para publicação: 25/02/2015 - Aceito para publicação: 20/12/2016

\begin{abstract}
Resumo
Avaliou-se a dinâmica da biomassa e do carbono no componente arbóreo acima do solo em um fragmento de Floresta Ombrófila Mista Montana no sul do Brasil. Os dados foram coletados em quatro parcelas permanentes instaladas no ano de 1995 com medições anuais até o ano de 2012. Indivíduos arbóreos com diâmetro à altura do peito (DAP) $\geq 10 \mathrm{~cm}$ foram mensurados. As árvores mortas e os indivíduos recrutas foram registrados em cada avaliação. Estimou-se a biomassa e o carbono orgânico ao nível de família, espécie e classe diamétrica. O estoque de biomassa acima do solo em árvores vivas foi estimado em $174,5 \mathrm{Mg} \mathrm{ha}^{-1}$ no ano de 1995 e de $235,4 \mathrm{Mg} \mathrm{ha}^{-1}$ para o ano de 2012 , correspondendo a $73,14 \mathrm{Mg} \mathrm{ha}^{-1} \mathrm{e}$ $98,66 \mathrm{Mg} \mathrm{ha}^{-1}$ de carbono, respectivamente. O incremento periódico anual (IPA) foi de $3,58 \mathrm{Mg} \mathrm{ha}^{-1} \mathrm{ano}^{-1} \mathrm{de}$ biomassa e $1,49 \mathrm{Mg} \mathrm{ha}^{-1} \mathrm{ano}^{-1}$ de carbono. O grupo das Araucárias apresentou maior estoque tanto em biomassa quanto em carbono. Entre as famílias, destacaram-se Araucariaceae e Lauraceae, e entre espécies Araucaria angustifolia. Avaliando a distribuição espacial das variáveis, contatou-se que os estoques de biomassa e carbono se mostraram muito associados à presença de Araucaria angustifolia.

Palavras-chave: Inventário florestal; fitomassa; crescimento; recrutamento; mortalidade.
\end{abstract}

\section{Abstract}

Tree biomass and carbon dynamics between 1995-2012 in a Mountain Araucaria Forest. This work aimed to study the dynamics of biomass and carbon in the tree component aboveground in a fragment of Montane Araucaria Forest in São João do Triunfo - Paraná. We evaluated four permanent sample plots established in 1995 with yearly measurements by the year 2012 . Individual trees with $\mathrm{dbh} \geq 10 \mathrm{~cm}$ were considered, and they are identified botanically. Dead trees and recruits individuals were recorded. It has been estimated the biomass and carbon stocks for species groups, families, species and diameter classes. The stock of aboveground biomass in living trees was estimated at $174.5 \mathrm{Mg} \mathrm{ha}^{-1}$ in 1995 and $235.4 \mathrm{Mg} \mathrm{ha}^{-1}$ for the year 2012 , corresponding to $73.14 \mathrm{Mg} \mathrm{ha}^{-1}$ and $98.66 \mathrm{Mg} \mathrm{ha}^{-1}$ of carbon, respectively, representing an annual periodic increment (IPA) of $3.58 \mathrm{Mg} \mathrm{ha}^{-1}$.year ${ }^{-1}$ in biomass and $1.49 \mathrm{Mg} \mathrm{ha}^{-1}$ year $^{-1}$ in carbon. The Araucaria group had a higher stock of both biomass andcarbon. Among families, stood out Araucariaceae and Lauraceae, and between species Araucaria angustifolia. Assessing the spatial distribution of variables were contacted that the biomass and carbon stocks were very associated with the presence of Araucaria angustifolia.

Keywords: Forest inventory; phytomass; growth; recruitment; mortality.

\section{INTRODUÇÃO}

A Floresta Ombrófila Mista (FOM), também conhecida como Floresta com Araucária, tem em sua constituição arbórea a espécie característica Araucaria angustifolia (Bertol.) Kuntz, e encontra-se distribuída no planalto Sul Brasileiro, na província de Misiones (Argentina), no sul do estado de São Paulo e na Serra da Mantiqueira (IBGE, 1992). No entanto, devido à pressão da urbanização e abertura de áreas agrícolas, associadas a um intenso processo de extrativismo, a área da FOM encontra-se atualmente bastante reduzida e fragmentada, restando poucos remanescentes primários (SONEGO et al., 2007).

Paralelamente ao tema de qualidade ambiental global, questões climáticas ligadas ao aumento da concentração de gases do efeito estufa, principalmente o $\mathrm{CO}_{2}$ (Dióxido de carbono) e o conceito de sequestro de carbono tem sido cada vez mais discutidas na ciência e com isso, o potencial das florestas na fixação de carbono em sua biomassa passou a ser destacado. Mognon (2011) explica que por meio da fotossíntese, as florestas

FLORESTA, Curitiba, PR, v. 47, n. 2, p. 197 - 206, abr. / jun. 2017.

Lipinski, E. T. et al.

ISSN eletrônico 1982-4688

DOI: $10.5380 /$ rf.v47i1.40024 
conseguem absorver e armazenar átomos de carbono em seus tecidos estruturais, realizando assim, um dos serviços ambientais mais importantes e essenciais a vida de todos os seres vivos do planeta. Sendo assim, durante o crescimento das plantas, a biomassa é acumulada e, consequentemente, mais carbono é fixado.

Contudo, apesar da elevada relevância com que esse tema é tratado, Ratuchne (2010) menciona que a grande maioria dos trabalhos com a biomassa florestal é realizada em plantações florestais, sendo pequena a quantidade de trabalhos de quantificação ou estimativa da biomassa em florestas naturais. Essas informações indicam a necessidade do estabelecimento de rotinas para obtenção de informações científicas com o propósito de entender a complexidade desses ecossistemas, pois ainda muitas incertezas rodeiam a dinâmica do estoque de biomassa e do carbono das florestas. Mognon (2011) aponta que o conhecimento a respeito da dinâmica da floresta permite a interpretação do contexto da vegetação ao longo do tempo e que, com essa compreensão da dinâmica, pode-se conhecer melhor essa complexa estrutura autótrofa, podendo assim verificar o potencial de serviços ambientais prestados por ela.

Os processos dinâmicos da floresta, bem como seus aspectos florísticos e estruturais, são importantes indicadores das condições de conservação e do estágio sucessional em que se encontra um determinado remanescente (CORTE et al., 2014). Portanto, o monitoramento de remanescentes florestais a longo prazo é uma das principais ferramentas no auxílio à compreensão de seus processos dinâmicos, em especial àqueles relacionados à participação das florestas no ciclo de carbono, dada a sua importância atual.

O estudo da dinâmica de florestas ao longo do tempo permite também desenvolver mecanismos que garantam a manutenção da biodiversidade em condições futuras a partir da análise atual do comportamento das espécies quanto às mudanças no ambiente (KUULUVAINENE; AAKALA, 2011). Tais estudos permitem a compreensão de uma gama de processos envolvendo a autoecologia e sinecologia das comunidades vegetais.

Amaral et al. (2010) afirmam que muitos estudos são realizados sem considerar a dependência espacial que existe para as variáveis de uma floresta, ou ainda sem se preocupar com a sua representação no espaço. Estima-se que mais de $80 \%$ das publicações na área ecológica não consideram a estrutura de dependência espacial (DORMANN, 2007).

Este trabalho tem como propósito avaliar a dinâmica temporal e espacial da biomassa e do carbono da parte aérea do componente arbóreo ao longo de 17 anos em um fragmento de Floresta Ombrófila Mista, no período entre 1995 e 2012. Também foi alvo deste trabalho, a avaliação em termos de contribuição dos grupos ecológicos, famílias, espécies e classes diamétrica, na dinâmica da biomassa e do carbono florestal.

\section{MATERIAL E MÉTODOS}

Para o desenvolvimento do trabalho foram utilizados dados de parcelas permanentes pertencentes ao Projeto Ecológico de Longa Duração (PELD) - Sitio 9 (Floresta com Araucária e suas transições), instaladas na estação experimental da Universidade Federal do Paraná, no município de São João do Triunfo - estado do Paraná, Brasil.

\section{Caracterizações da área de estudo}

A estação experimental está a 780 m de altitude. De acordo com a classificação climática de Köppen, o clima da região é do tipo $\mathrm{Cfb}$, caracterizado por ser mesotérmico, sempre úmido e com verões brandos.

O solo predominante é do tipo Argissolo Vermelho-Amarelo distrófico, sendo encontrado também em pequena proporção Cambissolo distrófico álico.

Segundo a classificação proposta pelo IBGE (1992), a tipologia vegetal dominante na área é a Floresta Ombrófila Mista Montana. Em algumas partes da área experimental, apesar da floresta não ter sofrido cortes rasos, sofreu algumas intervenções, que podem ser constatadas em Schaaf (2006).

\section{Origem dos dados e tratamento estatístico}

Os dados utilizados neste trabalho advêm de quatro parcelas permanentes instaladas em 1995 e avaliadas anualmente conforme especificações de Sanquetta (2008). Para o presente trabalho foram utilizados dados referentes aos anos de 1995 a 2012, constituindo 17 anos de monitoramento.

A área total de estudo corresponde a 3,5 hectares, ou seja, três parcelas de um hectare $(100 \mathrm{~m} \times 100 \mathrm{~m}) \mathrm{e}$ uma com 0,5 ha. Todas as árvores com diâmetro à altura do peito (dap) maior ou igual a $10 \mathrm{~cm}$ foram identificadas.

Os indivíduos contabilizados foram identificados conforme espécie, gênero e família botânica. A maioria dos indivíduos encontrados foi identificada in loco, e para os não identificados, procedeu-se a coleta de ramos e folhas para a posterior determinação em laboratório. As espécies foram classificadas dentro das famílias reconhecidas pelo sistema Angiosperm Phylogeny Group III (APG III, 2009).

$\mathrm{O}$ dap de todas as árvores foi medido anualmente no período avaliado, sempre no inverno (mês de julho), utilizando-se fita diamétrica. Árvores mortas, bem como os indivíduos que passaram a atingir o tamanho 
mínimo de medição a cada ocasião (ingressos), foram registradas e computadas.

A dinâmica foi avaliada por meio da análise do acúmulo e taxas de incremento em biomassa e carbono, com ênfase nos grupos ecológicos (assim denominados o grupo de indivíduos da espécie Araucária - Araucárias, grupo de indivíduos da família Lauraceae - Canelas, e demais espécies - Outras), famílias, espécies e classes diamétricas. Com base nos dados do inventário de 1995 e 2012, empregou-se equações desenvolvidas para a mesma tipologia deste estudo, conforme os autores Pizatto (1999), Ratuchne (2010), Mognon et al. (2013) e Watzlawick et al. (2002), apresentadas na tabela 1.

Tabela 1. Equações para estimativa da biomassa e carbono em um remanescente de Floresta Ombrófila Mista, no período de 17 anos.

Table 1. Equations for estimates of variables analyzed in the dynamics of biomass and carbon in a Araucaria Forest patch, monitored for 17 years.

\begin{tabular}{lcc}
\hline & Altura & \\
\hline Araucária & $H T=15,84375-3698530\left(\frac{1}{\text { dap }}\right)+0,13460$ dap & 2 \\
Outras & $H T=-2,11355+5,66076 \ln ($ dap $)$ & 3 \\
\hline & Biomassa & \\
\hline Carbono & 4 \\
\hline Acúmulo & Acúmulo de biomassa e carbono total & \\
\hline Taxa de acúmulo & $A B C t=B C_{2012}-B C_{1995}$ & 5 \\
\hline & $T B C t(\%)=\frac{A B C t}{17} 100$ & 6
\end{tabular}

\begin{tabular}{lcc}
\hline & Biomassa e Carbono entre os grupos ecológicos & 7 \\
\hline Incremento total & $I g=E g_{2012}-E g_{1995}$ & 8 \\
Taxa de incremento & $T B C g(\%)=\frac{I g}{17} 100$ & 9 \\
\hline Bncremento total & $T B C f(\%)=\frac{I f}{17} 100$ & 10 \\
Taxa de incremento & Biomassa e Carbono entre as famílias & 11 \\
\hline Incremento total & Biomassa e carbono entre as espécies & 12
\end{tabular}

\begin{tabular}{lcc}
\hline & Biomassa e carbono entre as classes diamétricas & 13 \\
\hline Taxa de incremento & $B C d i=B C d i_{2012}-B C d i_{1995}$ & 14 \\
Incremento total & $T B C d i(\%)=\frac{A B C d i}{17} 100$ & \\
$\begin{array}{l}\text { Em que: ht }=\text { altura total }(\mathrm{m}) ; \mathrm{B}=\text { biomassa }(\mathrm{Mg}) ; \mathrm{C}=\text { Carbono }(\mathrm{Mg}) ; \mathrm{ABC}=\text { Acúmulo em biomassa e carbono }(\mathrm{Mg}) ; \mathrm{TBC}=\text { Taxa de } \\
\text { incremento em biomassa e carbono }(\%) .\end{array}$
\end{tabular}

FLORESTA, Curitiba, PR, v. 47, n. 2, p. 197 - 206, abr. / jun. 2017.

Lipinski, E. T. et al.

ISSN eletrônico 1982-4688

DOI: $10.5380 /$ rf.v47i1.40024 


\section{Distribuição espacial}

Com base nas coordenadas de cada parcela foram gerados mapas temáticos da distribuição espacial do estoque de biomassa e carbono por meio do software ArcGis 9, tendo como objetivo visualizar a distribuição espacial da biomassa e do carbono total no conjunto de dados das quatro parcelas denominadas: Araucária, Imbuia, Fogo e Rio. As três primeiras parcelas citadas possuem um hectare cada, com 100 subdivisões, sendo denominadas subparcela com $100 \mathrm{~m}^{2}$ cada. A parcela Rio possui 0,5 ha, com 50 subparcelas de $100 \mathrm{~m}^{2}$. Para tal representação, realizou-se o somatório do estoque de biomassa e carbono em cada subparcela e foi aplicada uma simbologia gráfica para cada classe avaliada. As classes adotadas para os estoques de biomassa foram: 1 (0$500 \mathrm{~kg}), 2(500,1-2000 \mathrm{~kg}), 3(2000,1-4000 \mathrm{~kg}), 4(4000,1-6000 \mathrm{~kg})$ e por fim a classe $5(>6000 \mathrm{~kg})$. E na avaliação de carbono utilizaram-se as classes: 1 (0-250 kg), $2(250,1-1000 \mathrm{~kg}), 3(1000,1-2000 \mathrm{~kg}), 4$ (2000,1$3000 \mathrm{~kg})$ e a classe 5 (>3000 kg).

\section{RESULTADOS E DISCUSSÃO}

A biomassa total média estocada em árvores vivas foi estimada em 174,5 $\mathrm{Mg} \mathrm{ha}^{-1}$ para o ano de $1995 \mathrm{e}$ de 235,4 $\mathrm{Mg} \mathrm{ha}^{-1}$ para 2012, representando um aumento no estoque de biomassa arbórea acima do solo na ordem de $3,58 \mathrm{Mg} \mathrm{ha}^{-1} \mathrm{ano}^{-1}$. O estoque de carbono nas árvores vivas, para o ano de 1995 foi de $73,14 \mathrm{Mg} \mathrm{ha}^{-1} \mathrm{e}$ $98,66 \mathrm{Mg} \mathrm{ha}^{-1}$ para o ano de 2012, o que corresponde a um aumento no carbono estocado de $1,49 \mathrm{Mg} \mathrm{ha}^{-1} \mathrm{ano}^{-1}$. Resultados esses, muito semelhante aos observados por Weber et al. (2005), onde o aumento nos estoques estimado por estes autores também foi de $1,5 \mathrm{Mg} \mathrm{ha}^{-1} \mathrm{ano}^{-1}$ para o mesmo remanescente, no entanto entre o período de 1997 a 2005, sendo o estoque de biomassa de 252,38 $\mathrm{Mg} \mathrm{ha}^{-1}$ e de carbono de $104,32 \mathrm{Mg} \mathrm{ha}^{-1} \mathrm{no}$ último ano estudado, indicando certa estabilidade nos estoques ao longo do tempo.

Nesta mesma tipologia florestal, em General Carneiro, PR, Mognon (2011) estimou a biomassa e o carbono, encontrando $186,75 \mathrm{Mg} \mathrm{ha}^{-1}$ e 77,53 $\mathrm{Mg} \mathrm{ha}^{-1}$ respectivamente. No estudo supracitado, o autor encontrou um incremento anual de biomassa e carbono do componente arbóreo acima do solo de 0,75 e $0,31 \mathrm{Mg} \mathrm{ha}^{-1} \mathrm{ano}^{-1}$ respectivamente. Ainda nesta mesma região, porém em outras parcelas, Watzlawick et al. (2002), encontraram para diferentes estágios sucessionais: inicial, médio e avançado, respectivamente, 69,37, 168,84 e 397,79 Mg.ha ${ }^{-}$ ${ }^{1}$ de biomassa acima do solo, correspondendo a 28,84, 70,23 e 165,02 $\mathrm{Mg} \mathrm{ha}^{-1}$ de carbono estocado. Os valores obtidos no presente trabalho indicam que a floresta deste estudo se encontra em estágio médio tendendo ao avançado, quando comparados seus estoques aos valores referenciados em literatura.

No entanto, cabe destacar que existem muitas diferenças nos estoques de biomassa e carbono em função de várias condições, como por exemplo, diferentes tipologias, ecossistemas, histórico de manejo florestal aplicado nessas áreas e também os diferentes métodos de quantificação e intensidade amostral.

Entre os grupos de espécies avaliados, o das Araucárias, em todos os anos, apresentou o maior estoque de biomassa e carbono, seguido do grupo Outras e por fim o grupo Canelas (Tabela 2). Estes grupos, apresentaram média de 52\%, 29\% e 19\%, respectivamente, para o período estudado (1995 até 2012) de participação no estoque de biomassa e $53 \%$, 29\% e $18 \%$ para o estoque de carbono para o mesmo período. As pequenas diferenças em relação ao estoque de biomassa observadas devem-se aos diferentes teores de carbono utilizados para cada grupo. Mognon (2011) na mesma tipologia florestal deste estudo, no município de General Carneiro, observou que em média 36\% do total da biomassa da floresta foram representados pelo grupo das Araucárias, 32\% das Brancas (demais espécies) e 32\% pelo grupo das Canelas. A diferença observada em relação ao presente trabalho deve-se à densidade de indivíduos dos diferentes grupos, em que neste trabalho foi maior para o grupo das Araucárias e menor para o grupo das Canelas, em relação ao encontrado pelo autor acima mencionado.

Tabela 2. Estoques e incremento de biomassa e carbono nos grupos estudados durante o período de 17 anos em um remanescente de Floresta Ombrófila Mista.

Table 2. Biomass and carbon stocks and increment in the studied groups, evaluated for 17 years in a Araucaria Forest patch.

\begin{tabular}{|c|c|c|c|c|c|c|}
\hline \multirow{2}{*}{ Grupo } & \multicolumn{2}{|c|}{ Biomassa $\left(\right.$ Mg.ha $\left.^{-1}\right)$} & \multirow{2}{*}{$\begin{array}{c}\text { Incremento } \\
\left(\mathrm{Mg} \mathrm{ha}^{-1} \mathrm{ano}^{-1}\right)\end{array}$} & \multicolumn{2}{|c|}{ Carbono $\left(\mathrm{Mg.ha}^{-1}\right)$} & \multirow{2}{*}{$\begin{array}{c}\text { Incremento } \\
\left(\text { Mgha }^{-1} \text { ano }^{-1}\right)\end{array}$} \\
\hline & 1995 & 2012 & & 1995 & 2012 & \\
\hline Araucárias & 102,5 & 126,8 & 1,43 & 43,7 & 54,0 & 1,17 \\
\hline Canelas & 42,0 & 40,7 & $-0,07$ & 17,1 & 16,6 & $-0,01$ \\
\hline Outras & 66,3 & 68,3 & 0,12 & 27,3 & 28,1 & 0,01 \\
\hline
\end{tabular}

Considerando apenas as mudanças de biomassa nas árvores vivas, notou-se um incremento de acúmulo para a biomassa de $1,5,1,3$ e $0,75 \mathrm{Mg} \mathrm{ha}^{-1}$ ano $^{-1}$ e para o estoque de carbono $0,65,0,54$ e $0,31 \mathrm{Mg} \mathrm{ha}^{-1}$ ano $^{-1}$ aos grupos: Araucária, Outras e Canelas, respectivamente (Figura 1). Avaliou-se ainda, a contribuição da 
mortalidade na dinâmica da biomassa e do carbono seguindo os resultados, para a biomassa: Araucária com 0,09, Outras com 1,19 e Canelas com $0,83 \mathrm{Mg} \mathrm{ha}^{-1} \mathrm{ano}^{-1}$. Para o carbono, a contribuição da mortalidade foi: Araucária com 0,04, Outras com 0,49 e Canelas com 0,34 $\mathrm{Mg} \mathrm{ha}^{-1}$ ano $^{-1}$.

Mognon (2011) encontrou para estes grupos, respectivamente, incremento em biomassa de 0,48, $-0,03 \mathrm{e}$ 0,3 $\mathrm{Mg} \mathrm{ha}^{-1} \mathrm{ano}^{-1}$, ou seja, a floresta em estudo não segue a mesma tendência, evidenciando estar em mudanças de outra ordem em relação ao estudo comparativo, uma vez que existem diferenças em sua composição florística e estrutura. Em relação ao carbono, a taxa de acúmulo foi na ordem de 0,61 para o grupo das Araucárias, 0,37 para Canelas e $0,05 \mathrm{Mg} \mathrm{ha}^{-1} \mathrm{ano}^{-1}$ para o grupo das Outras. Ainda, considerando árvores vivas e ingressas no período, a mudança foi na ordem de $0,6 \mathrm{Mg} \mathrm{ha}^{-1} \mathrm{ano}^{-1}$ de carbono para o grupo das Araucárias, $0,69 \mathrm{Mg} \mathrm{ha}^{-1} \mathrm{ano}^{-1}$ para Canelas e $0,5 \mathrm{Mg} \mathrm{ha}^{-1} \mathrm{ano}^{-1}$ para as Outras.

Seguindo a tendência dos grupos, as famílias Araucariaceae e Lauraceae (representantes dos grupos Araucária e Canelas) foram as que apresentaram os maiores estoques de biomassa e carbono ao longo do período estudado. Estas duas famílias representam juntas em torno de $70 \%$ de biomassa e do carbono total fixado. Segundo Mognon et al. (2013), as espécies Araucaria angustifolia e Ocotea porosa são as principais espécies representantes das famílias Araucariaceae e Lauraceae, respectivamente, destacando-se por serem as espécies com grande valor de importância na Floresta Ombrófila Mista, mas também, por contribuírem significativamente nos estoques e no incremento em biomassa e carbono nas florestas que se encontram.

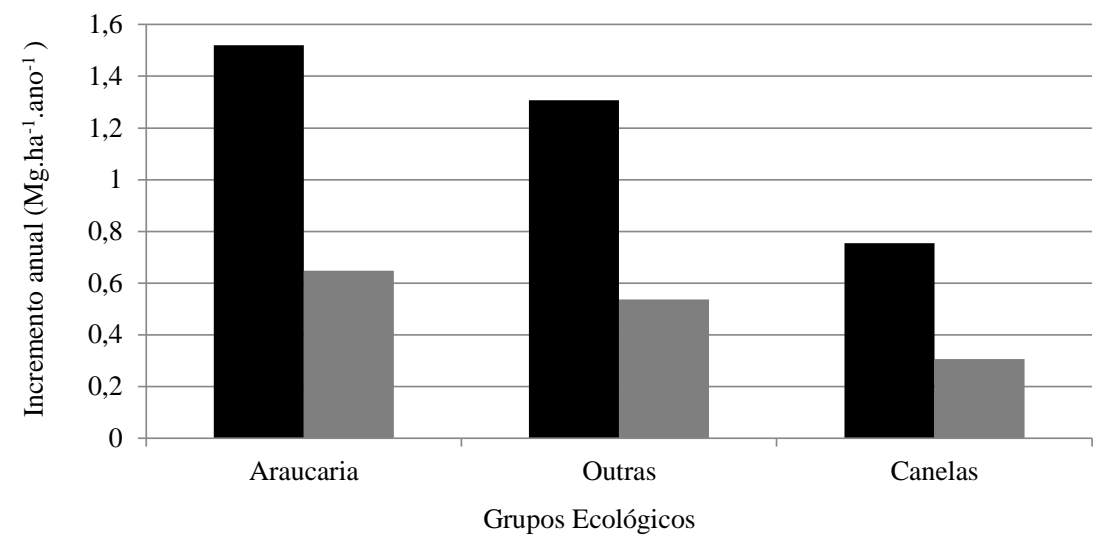

- Biomassa acima do solo de árvores vivas

- Carbono acima do solo de árvores vivas

Figura 1. Incremento em biomassa e carbono de árvores vivas em toneladas por hectare distribuídas por grupo ecológico no período entre 1995 e 2012.

Figure 1. Biomass and carbon increment in living trees according to ecological groups between the years 1995 and 2012 .

Ainda, merece destaque a família Sapindaceae, que foi a terceira família a apresentar maior biomassa,

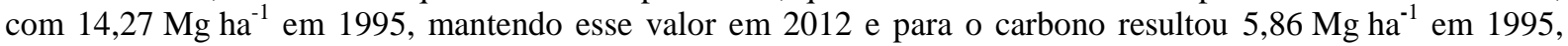
mantendo em 2012 os mesmos valores. Porém vale ressaltar, que esta família apresenta apenas 6,3\% da biomassa total e também do carbono total durante o período estudado. Araucariaceae e Lauraceae apresentaram também os maiores incrementos anuais de estoque de biomassa e do carbono fixado em árvores vivas. A família Araucariaceae apresentou $1,52 \mathrm{Mg} \mathrm{ha}^{-1} \mathrm{ano}^{-1}$ e $0,65 \mathrm{Mg} \mathrm{ha}^{-1} \mathrm{ano}^{-1}$ para biomassa e carbono, respectivamente e Lauraceae $0,76 \mathrm{Mg} \mathrm{ha}^{-1} \mathrm{ano}^{-1}$ e $0,31 \mathrm{Mg} \mathrm{ha}^{-1}$ ano $^{-1}$ de biomassa e carbono, respectivamente. Na figura 2 encontrase a predominância dessas famílias em relação as demais. A família Myrtaceae apresentou, em terceiro lugar, incremento de $0,19 \mathrm{Mg} \mathrm{ha}^{-1} \mathrm{ano}^{-1}$ e $0,08 \mathrm{Mg} \mathrm{ha}^{-1} \mathrm{ano}^{-1}$ de biomassa e carbono, respectivamente. 


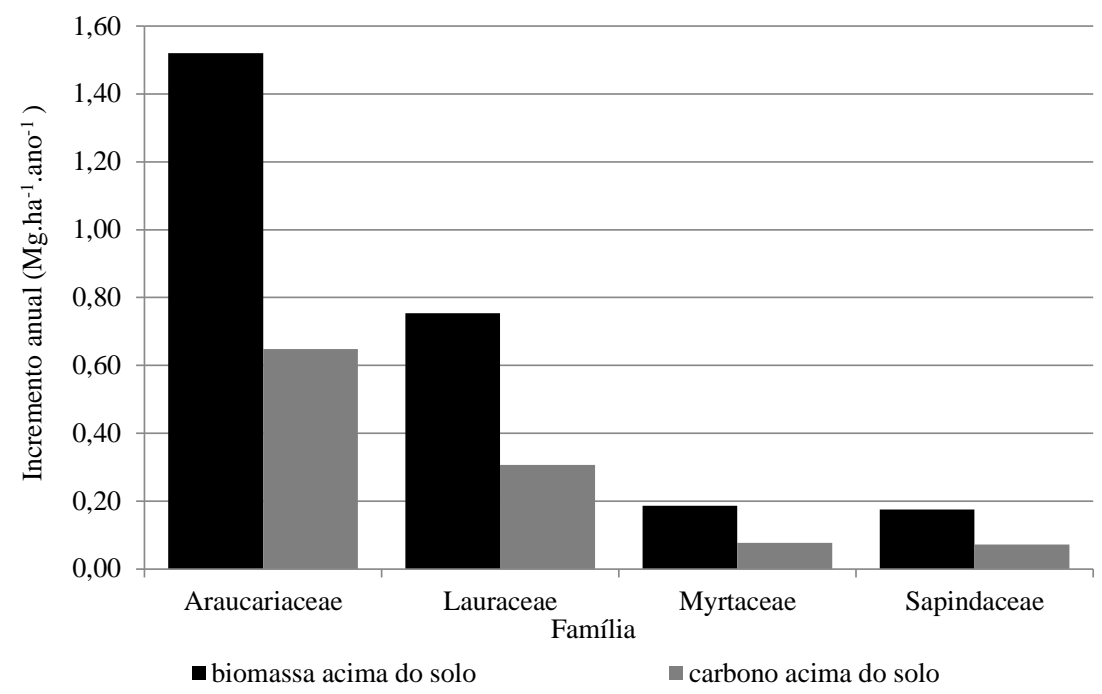

Figura 2. Incremento em biomassa e carbono de árvores vivas em toneladas por hectare das principais famílias no período entre 1995 e 2012.

Figure 2. Biomass and carbon increment in living trees from the main botanical families between the years 1995 and 2012.

Destaca-se que ao longo do período estudado, algumas famílias deixaram de acumular biomassa e carbono, devido à mortalidade de indivíduos e também pela baixa taxa de crescimento dos indivíduos ingressados, como é o caso das famílias: Lauraceae, Canellaceae, Rubiaceae, Aquifoliaceae, Anacardiaceae, Asteraceae e Primulaceae. Tal situação pode indicar alterações nos padrões florísticos e estruturais do remanescente, em função de modificações na dinâmica sucessional.

$\mathrm{Na}$ floresta, a espécie com o maior acúmulo de biomassa foi A.angustifolia, que representou média de $52 \%$ do estoque total de biomassa. Ainda merecem destaque as espécies Ocotea porosa, Matayba elaegnoides e Nectandra grandiflora. Para o carbono, A. angustifolia destacou-se com média de 53\% do estoque total de carbono, seguinda também das espécies. Ocotea porosa, Matayba elaeagnoides e Nectandra grandiflora (Tabela 3). Mognon (2011), através de uma analogia dentro de cada grupo ecológico, destacou as espécies Araucaria angustifolia, Ilex paraguariensis e Ocotea porosa, como sendo as mais representativas no acúmulo de biomassa para sua área de estudo.

Tabela 3. Estoques e incremento em biomassa e carbono das principais espécies de um remanescente de Floresta Ombrófila Mista monitorada por 17 anos.

Table 3. Biomass and carbon stocks and increment of the main species in an Araucaria Forest patch monitored for 17 years.

\begin{tabular}{|c|c|c|c|c|c|c|}
\hline \multirow{2}{*}{ Espécie } & \multicolumn{2}{|c|}{ Biomassa $\left(\mathrm{Mg} \mathrm{ha}^{-1}\right)$} & \multirow{2}{*}{$\begin{array}{c}\text { Incremento } \\
\left(\text { Mg.ha }^{-1} \text { ano }^{-1}\right)\end{array}$} & \multicolumn{2}{|c|}{ Carbono $\left(\mathrm{Mg.ha}^{-1}\right)$} & \multirow{2}{*}{$\begin{array}{l}\text { Incremento } \\
\left(\mathrm{Mg} \mathrm{ha}^{-1} \mathrm{ano}^{-1}\right)\end{array}$} \\
\hline & 1995 & 2012 & & 1995 & 2012 & \\
\hline Araucaria angustifolia & 102,47 & 126,82 & 1,43 & 43,65 & 54,02 & 0,61 \\
\hline Ocotea porosa & 15,71 & 17,3 & 0,09 & 6,39 & 7,04 & 0,04 \\
\hline Matayba elaegnoides & 13,16 & 13,25 & 0,01 & 5,41 & 5,45 & 0,00 \\
\hline Nectandra grandiflora & 6,42 & 11,34 & 0,29 & 2,61 & 4,62 & 0,12 \\
\hline
\end{tabular}

A estrutura da distribuição de biomassa e carbono por classe diamétrica da floresta não apresentou a típica distribuição em forma de "J", apresentando uma distribuição irregular, tendendo à normal, com assimetria à direita. Esse resultado decorre do fato de que, embora haja um número maior de indivíduos nas classes iniciais, o porte reduzido desses implica em pouca biomassa e carbono, enquanto as classes intermediárias embora apresentem menos indivíduos que as classes iniciais, esses apresentam maior porte e, consequentemente, maior estoque de biomassa e carbono. A assimetria à direita na distribuição da biomassa e carbono em função das classes diamétricas se dá pela existência de indivíduos de grande porte nas maiores classes responsáveis por grande acúmulo de biomassa (Figura 3 e 4).

Por meio da espacialização realizada foi possível observar que o estoque de biomassa e carbono não se 
distribuiu homogeneamente dentre (parcelas) e entre (subparcelas) as amostras. A Parcela Fogo apresentou maior homogeneidade dentre as quatro parcelas avaliadas, e foi considerada como a de menor biomassa, bem como, obteve menor estoque de carbono. Já a parcela Imbuia apresentou o maior estoque de biomassa e carbono (Figuras 5 e 6).

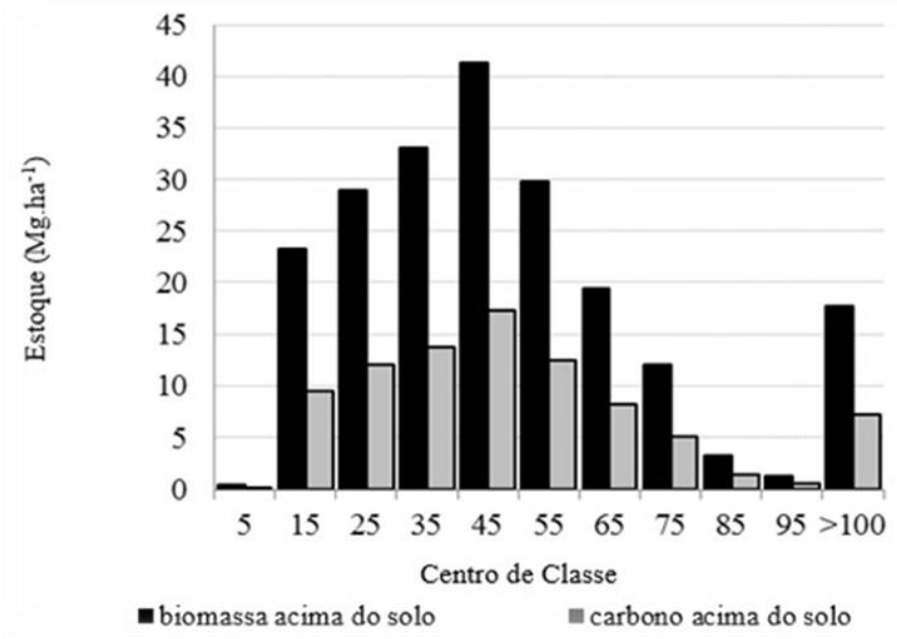

Figura 3. Estoque total de biomassa e carbono $\left(\mathrm{Mg} \mathrm{ha}^{-1}\right)$, distribuído em classes diamétricas no ano de 1995. Figure 3. Total biomass and carbon stocks $\left(\mathrm{Mg} \mathrm{ha}^{-1}\right)$, according to diametric classes for the year 1995.

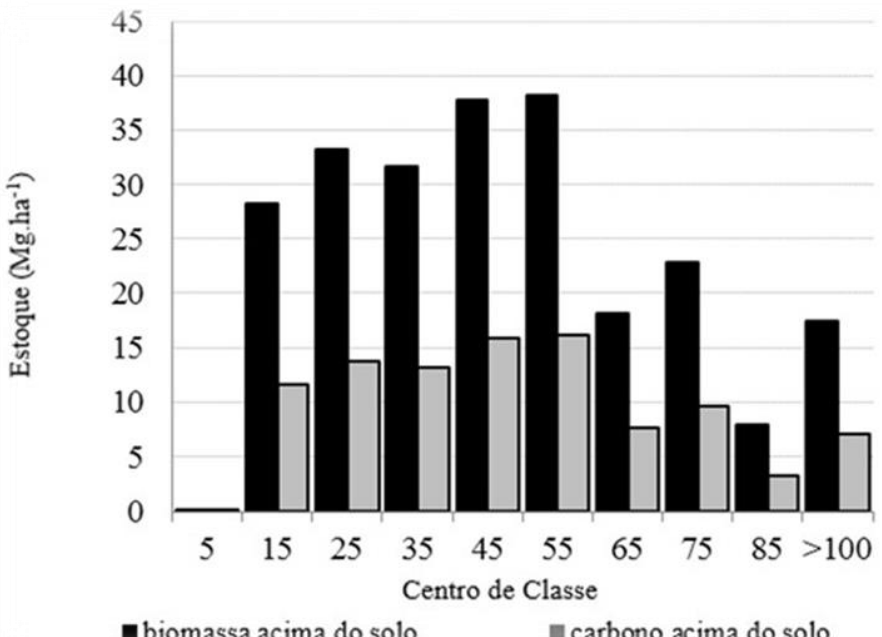

Figura 4. Estoque total de biomassa e carbono $\left(\mathrm{Mg} \mathrm{ha}^{-1}\right)$, distribuído em classes diamétricas no ano de 2012. Figure 4. Total biomass and carbon stocks $\left(\mathrm{Mg} \mathrm{ha}^{-1}\right)$, according to diametric classes for the year 2012.

Dentre as parcelas, os maiores estoques foram observados nas subparcelas com predomínio de indivíduos da espécie A. angustifolia. Nas demais parcelas que não contemplam esta espécie, a ocorrência de grandes quantidades de biomassa ocorreu principalmente em razão da presença de árvores de grande porte pertencentes ao grupo Canelas. Ao longo dos anos, a frequência das subparcelas para as diferentes classes de conteúdo de carbono não permaneceu constante, dada a dinâmica estrutural da floresta.

Considerando a parcela Araucária, observa-se que a segunda classe de concentração dos estoques, tanto de biomassa quanto de carbono, foi a mais expressiva, mantendo-se dominante no período entre 1995 e 2012 . Já na parcela Imbuia, a terceira classe de concentração dos estoques de biomassa foi a mais representativa em 1995, sendo substituída em 2012 pela segunda classe. Em relação aos estoques de carbono nessa parcela, a segunda classe manteve-se predominante no período considerado. Na parcela Fogo, o destaque das concentrações de biomassa e carbono, tanto em 1995 quanto em 2012, foi para a segunda classe. Por fim, na parcela Rio a segunda classe de concentração de biomassa foi dominante em 1995, sendo substituída em 2012 pela terceira classe. Em 
relação aos estoques de carbono na parcela Rio, observa-se que a segunda classe foi dominante em ambos os anos avaliados (Figuras 5 e 6).

Essa dinâmica do estoque de biomassa e carbono observada por meio da espacialização evidencia que muitas subparcelas, ou propriamente o fragmento estudado, possui potencial para estocar mais carbono, podendo alcançar ou até ultrapassar o valor encontrado por Watzlawick et al. (2002) de 165,02 $\mathrm{M} \mathrm{ha}^{-1}$ de carbono em estágio avançado.

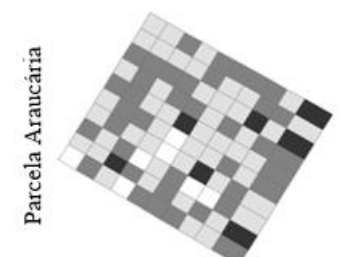

(a)

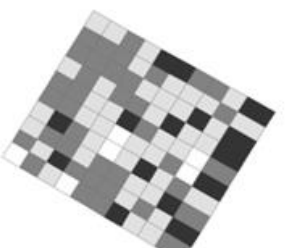

(b)

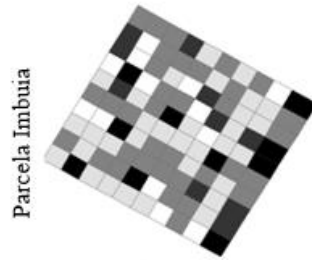

(c)

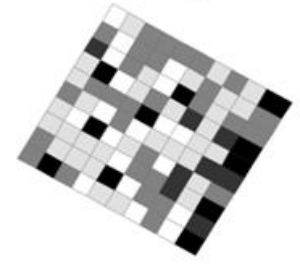

(d)

(e)

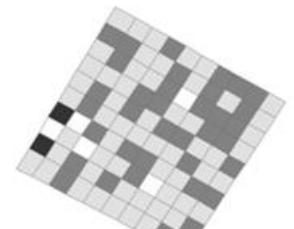

(f)

(g)
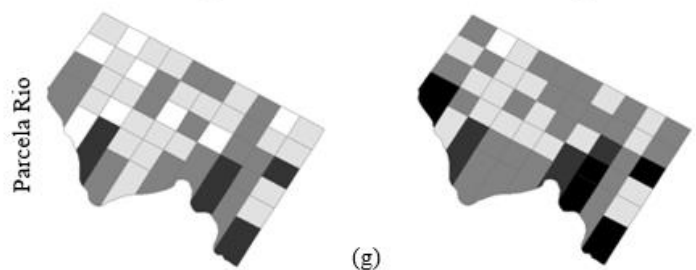

(h)

Biomassa kg. $\left(100 \mathrm{~m}^{2}\right)^{-1}$

$$
\begin{aligned}
& \square 0-1500 \\
& \square 500-\mid 2.000 \\
& \square .000-4.000 \\
& \square .000-16.000 \\
& \square=6.000
\end{aligned}
$$

\section{)

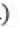

Figura 5. Distribuição espacial da biomassa em quilograma por $100 \mathrm{~m}^{2}$ : a) parcela Araucária de 1995; b) parcela Araucária 2012; c) parcela Imbuia de 1995; d) parcela Imbuia 2012; e) parcela Fogo de 1995; f) parcela Fogo 2012; g) parcela Rio de 1995; h) parcela Rio 2012.

Figure 5. Spatial distribution of biomass in $\mathrm{Kg}$ by $100 \mathrm{~m}^{2}$ : a) Araucaria plot in 1995; b) Araucaria plot in 2012; c) Imbuia plot in 1995; d) Imbuia plot in 2012; e) Fogo plot in 1995; f) Fogo plot in 2012; g) Rio plot in 1995; h) Rio plot in 2012. 


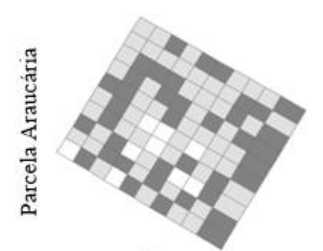

(a)

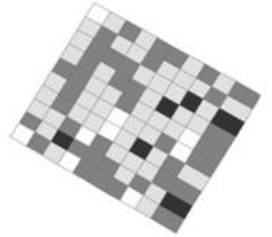

(b)
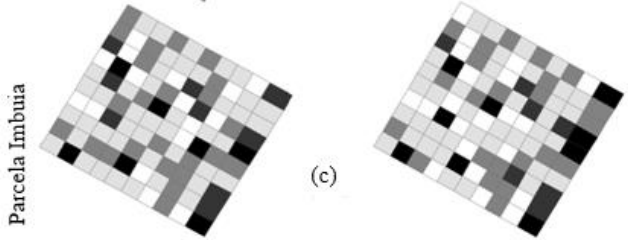

(d)
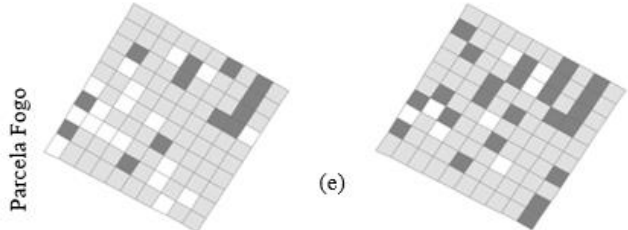

(f)
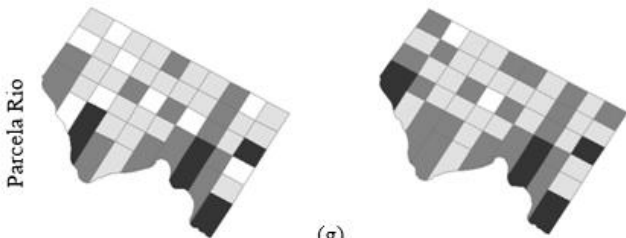

(g)

Carbono kg. $\left(100 \mathrm{~m}^{2}\right)^{-1}$

$$
\begin{aligned}
& \square 0-\mid 250 \\
& \square 250-1.000 \\
& \square \\
& 1.000-12.000 \\
& 2.000-13.000 \\
& \square 3.000
\end{aligned}
$$

Figura 6. Distribuição espacial do carbono em quilograma por $100 \mathrm{~m}^{2}$ : a) parcela Araucária de 1995; b) parcela Araucária 2012; c) parcela Imbuia de 1995; d) parcela Imbuia 2012; e) parcela Fogo de 1995; f) parcela Fogo 2012; g) parcela Rio de 1995; h) parcela Rio 2012.

Figure 6. Spatial distribution of carbon in Kg by $100 \mathrm{~m}^{2}$ : a) Araucaria plot in 1995; b) Araucaria plot in 2012; c) Imbuia plot in 1995; d) Imbuia plot in 2012; e) Fogo plot in 1995; f) Fogo plot in 2012; g) Rio plot in 1995; h) Rio plot in 2012.

\section{CONCLUSÕES}

- O fragmento de Floresta Ombrófila Mista Montana estudada apresenta uma taxa anual de fixação de carbono de 1,49 $\mathrm{Mg} \mathrm{ha}^{-1} \mathrm{ano}^{-1}$ em sua biomassa acima do solo. Tanto a biomassa como o estoque de carbono são dependentes da composição estrutural da floresta, sendo a espécie Araucaria angustifolia responsável pelos maiores estoques. Isso reflete na distribuição da biomassa e carbono ao nível de subparcela, uma vez que aquelas onde a densidade de indivíduos dessa espécie é maior apresentam também os maiores estoques.

- A distribuição da biomassa e carbono por classe diamétrica demonstrou-se irregular, tendendo à uma distribuição normal assimétrica à direita.

- Ao longo dos anos, a frequência das subparcelas para as diferentes classes de conteúdo de biomassa e carbono não permaneceu constante em algumas parcelas em razão da dinâmica estrutural da floresta.

\section{REFERÊNCIAS}

AMARAL L. P.; FERREIRA R. A.; WATZLAWICK L. F.; GENÚ A. M. Análise da distribuição espacial de biomassa e carbono arbóreo acima do solo em floresta Ombrófila mista. Ambiência, Guarapuava - PR, v. 6 Ed. Especial, p. 103-114. 2010.

ANGIOSPERM PHYLOGENY GROUP - APG - III. An update of the Angiosperm Phylogeny Group classification for the orders and families of flowering plants: APG III. Botanical Journal of Linnean Society v.

FLORESTA, Curitiba, PR, v. 47, n. 2, p. 197 - 206, abr. / jun. 2017.

Lipinski, E. T. et al.

ISSN eletrônico 1982-4688

DOI: $10.5380 /$ rf.v47i1.40024 
161, p. 105-121. 2009.

CORTE, A. P. D.; SANQUETTA, C. R.; RODRIGUES, A. L.; MOGNON, F. Dinâmica do crescimento, mortalidade e recrutamento na Floresta com Araucária. In: SANQUETTA, C. R.; CORTE, A. P. D.; RODRIGUES, A. L.; MOGNON, F. Floresta com Araucária: pesquisas ecológicas de longa duração. Curitiba, p. 60-82, 2014.

DORMANN, C. F. Effects of incorporating spatial autocorrelation into the analysis of species distribution data. Global Ecology and biogeography, Oxford, v. 16, p. 129-138. 2007.

INSTITUTO BRASILEIRO DE GEOGRAFIA E ESTAÍSTICA (IBGE). Manual técnico da vegetação brasileira. Rio de Janeiro: 1992. 92 p. (Série Manuais Técnicos em Geociências, 1).

KUULUVAINEN, T.; AAKALA, T. Natural forest dynamics in boreal Fennoscandia: a review and classification. Silva Fennica, v. 45, n. 5, p. 823-841, 2011.

MOGNON, F. Dinâmica do estoque de carbono como serviço ambiental prestado por um fragmento de Floresta Ombrófila Mista Montana localizada no sul do estado do Paraná. 142 f. Dissertação (Mestrado em Engenharia Florestal) - Setor de Ciências Agrárias, Universidade Federal do Paraná, Curitiba, 2011.

MOGNON, F.; DALLAGNOL, F. S.; SANQUETTA, C. R.; CORTE, A. P. D.; BARRETO, T. G. Uma década de dinâmica da fixação de carbono na biomassa arbórea em floresta Ombrófila Mista no Sul do Paraná. Floresta, Curitiba, v. 43, p. 153-164, 2013.

PIZATTO, W. Avaliação biométrica da estrutura e da dinâmica de uma Floresta Ombrófila Mista em São João do Triunfo - PR: 1995 a 1999. 170f. Dissertação (Mestrado em Ciências Florestais) - Setor de Ciências Agrárias, Universidade Federal do Paraná. Curitiba, 1999.

RATUCHNE, L. C. Ajuste e seleção de equações alométricas para a estimativa de biomassa, carbono e nutrientes em uma Floresta Ombrófila Mista. 102 f. Dissertação (Mestrado em Agronomia) - Setor de Ciências Agrárias, UNICENTRO/PR, Guarapuava, 2010.

SANQUETTA, C. R.; DALLA CORTE, A. P.; EISFELD, R. L. Crescimento, mortalidade e recrutamento em duas florestas de araucária (Araucaria angustifolia (Bert.) O. Ktze.). no Estado do Paraná, Brasil. Revista Ciências Exatas e Naturais, v. 5, n. 1, p. 101-112, 2003.

SANQUETTA, C. R.; FERNANDES, L. A. V.; MIRANDA, D. L. C.; MOGNON, F. Inventário de plantas fornecedoras de produtos não madeireiros da floresta Ombrófila Mista no Estado do Paraná. Scientia Agraria, v. 11, p. 359-369, 2010.

SCHAAF, L. B.; FIGUEIREDO FILHO, A.; GALVÃO, F.; SANQUETTA, C. R. Alteração na estrutura diamétrica de uma floresta ombrófila mista no período entre 1979 e 2000 . Revista Árvore, v. 30, n. 2, p. 283295,2006

SONEGO, R. C.; BACKES, A.; SOUZA, A. F. Descrição da estrutura de uma Floresta Ombrófila Mista, RS, Brasil, utilizando estimadores não-paramétricos de riqueza e rarefação de amostras. Acta Botanica Brasilica, v. 21, n. 4, p. 943-955, 2007.

WATZLAWICK, L. F.; KIRCHNER. F. F.; SANQUETTA, C. R.; SCHUMACHER, M. V. O Papel do Sensoriamento Remoto nos Estudos de carbono. In: SANQUETTA, C. R. et al. (Eds). As Florestas e o Carbono. Curitiba, p. 215-235, 2002.

WEBER, K. S.; SANQUETTA, C. R.; EISFELD, R. L. Variação volumétrica e distribuição espacial do estoque de carbono em Floresta Ombrófila Mista. Revista Acadêmica Ciências Agrárias e Ambientais, Curitiba, v. 3, n. 2, p. 77-85, 2005. 